\title{
Aircraft testing of the new Blunt-body Aerosol Sampler (BASE)
}

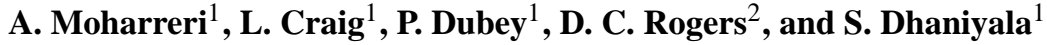 \\ ${ }^{1}$ Mechanical and Aeronautical Engineering Department, Clarkson University, Potsdam, NY, USA \\ ${ }^{2}$ Earth Observing Laboratory, NCAR/RAF, Broomfield, CO, USA
}

Correspondence to: S. Dhaniyala (sdhaniya@clarkson.edu)

Received: 20 February 2014 - Published in Atmos. Meas. Tech. Discuss.: 18 March 2014

Revised: 11 August 2014 - Accepted: 11 August 2014 - Published: 23 September 2014

\begin{abstract}
There is limited understanding of the role of aerosols in the formation and modification of clouds, partly due to inadequate data on such systems. Aircraft-based aerosol measurements in the presence of cloud particles have proven to be challenging because of the problem of cloud droplet/ice particle shatter and the generation of secondary artifact particles that contaminate aerosol samples. Recently, the design of a new aircraft inlet, called the Blunt-body Aerosol Sampler (BASE), which enables sampling of interstitial aerosol particles, was introduced. Numerical modeling results and laboratory test data suggested that the BASE inlet should sample interstitial particles with minimal shatter particle contamination. Here, the sampling performance of the inlet is established from aircraft-based measurements. Initial aircraft test results obtained during the PLOWS (Profiling of Winter Storms) campaign indicated two problems with the original BASE design: separated flows around the BASE at high altitudes and a significant shatter problem when sampling in drizzle. The test data were used to improve the accuracy of flow and particle trajectory modeling around the inlet, and the results from the improved flow model were used to guide design modifications of the BASE to overcome the problems identified in its initial deployment. The performance of the modified BASE was tested during the ICE-T (Ice in Clouds Experiment - Tropics) campaign, and the inlet was seen to provide near shatter-free measurements in a wide range of cloud conditions. The initial aircraft test results, design modifications, and the performance characteristics of the BASE relative to another interstitial inlet, the submicron aerosol inlet (SMAI), are presented.
\end{abstract}

\section{Introduction}

Aerosol particles are important from a global climate perspective because of their role in modulating the extent of solar radiation received at Earth's surface. Aerosol particles can interact directly with solar radiation or indirectly, by acting as nuclei for the formation of cloud droplets. The latter contribution, referred to as the aerosol indirect effect, has significant influence on global climate, and its accurate representation in global models is important for accurate long-term climate change predictions (Forster et al., 2007; Lohmann and Feichter, 2005).

In global circulation models (GCMs), computational considerations require aerosol-cloud interactions to only be incorporated via simple parametric models. With existing parameterizations, the predictions of net radiative forcing associated with aerosol indirect effects can vary significantly (Forster et al., 2007; Penner et al., 2006). Testing and improvement of the parametric models will require comprehensive aerosol-cloud data from a wide range of cloud systems. Such data can be best acquired using instrumented aircraft. Representative sampling of aerosol from the atmosphere to instruments inside the aircraft cabin is complicated by the presence of cloud droplets or ice particles in the atmosphere. Impaction of cloud droplets/ice particles on aerosol inlets and the aircraft hull can result in their breakup and the subsequent generation of a large number of secondary particles (Korolev et al., 2011, 2013). The generation of these shatter particles results in the contamination of aerosol samples, making measurements of background condensation nuclei $(\mathrm{CN})$, or interstitial aerosol, in clouds largely impossible (Rogers, 2008; Korolev, 2005; Weber et al., 1998). The inability to make incloud aerosol measurements from aircraft has stymied efforts to fully understand aerosol-cloud systems. 


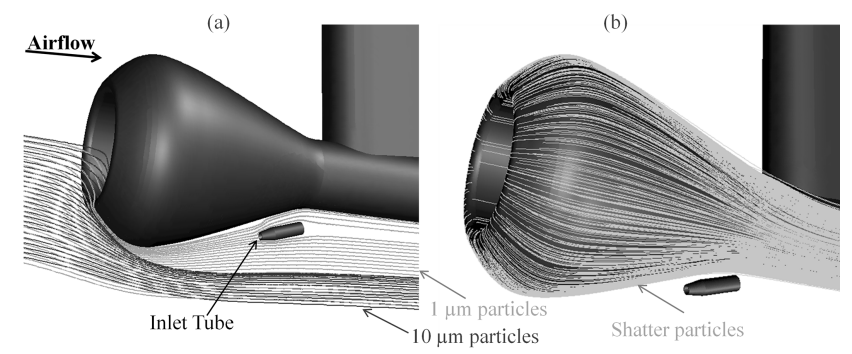

Figure 1. Design concept of the BASE; (a) trajectories of freestream particles around the sampler. Larger particles $(10 \mu \mathrm{m}$ diameter) are deflected from the inlet tube region while interstitial particles navigate around the blunt body and are present in the inlet tube region. (b) Shatter particles generated at the surface of the blunt body housing. These particles stay close to the surface of the body and do not enter the aerosol sample.

Recently, the design of a new aircraft inlet for aerosol measurements in clouds, called the Blunt-body Aerosol Sampler (BASE), was introduced (Moharreri et al., 2013). The BASE has a blunt body housing with a forward-facing inlet tube located in its aft region, as shown in Fig. 1. Critical to shatterfree sampling were the shape of the blunt body and the location of the inlet tube. The blunt body shape was optimized to ensure the deflection of cloud particles larger than $\sim 2 \mu \mathrm{m}$ away from the body surface in its aft region. An additional factor in the shape optimization was to maintain an attached boundary layer, i.e., ensure that the flow streamlines followed the curvature of the blunt body (Schlichting et al., 2004). With an attached boundary layer flow, shatter particles generated from the impaction of droplets on the blunt body were expected to remain in the flow closest to the body surface. Locating the inlet slightly above the surface of the blunt body and below the trajectory of the deflected cloud particles was expected to ensure the absence of cloud droplets and their shatter products from the inlet sample flow.

In the BASE design, it was expected that shatter particles larger than $\sim 1 \mu \mathrm{m}$ would escape the boundary layer flow and possibly be present in the flow entering the interstitial inlet. The presence of these particles was expected to become important when large cloud droplets and drizzle drops were present. The BASE design was, thus, expected to provide accurate interstitial aerosol sampling in clouds containing droplets but no drizzle drops. To minimize the surface area of the body where droplets can impact and shatter, the central region of the blunt body was hollowed out. The downstream end of the hollowed out region was connected to a flow pass-through tube to transport out any cloud and shatter particles away from this region (Fig. 2).

Moharreri et al. (2013) used computational fluid dynamics (CFD) modeling to arrive at the initial design of the BASE. The CFD predictions were validated with windtunnel measurements of flow fields and particle trajectories around the inlet. Flow visualization around the blunt body
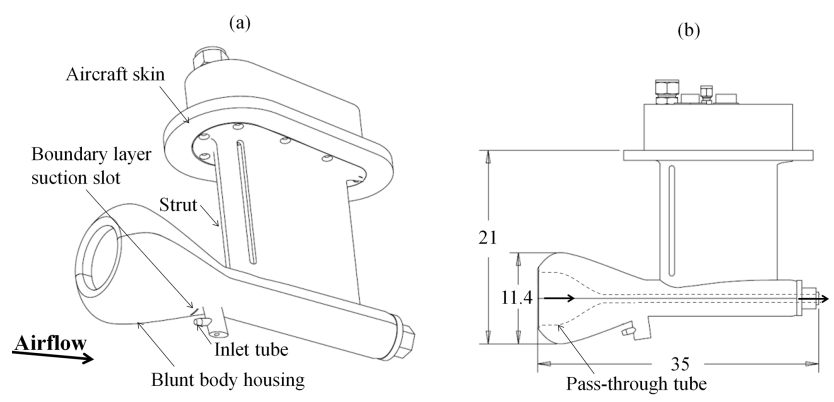

Figure 2. Design of the Blunt-body Aerosol Sampler (BASE-I) that was flown on the C-130 aircraft (dimensions in centimeters). (a) 3$\mathrm{D}$ view. (b) Side view. The interstitial inlet (labeled as inlet tube) is a stainless steel cylindrical tube with $1 / 4$ in. outer diameter and $3 / 16$ in. inner diameter.

confirmed that the boundary layer around the blunt body remained attached at Reynolds numbers consistent with typical C-130 operating conditions. Aerosol measurements in the wind-tunnel tests confirmed that small particles generated on the inlet surface remained outside the aerosol sample while larger shatter particles $(>\sim 1 \mu \mathrm{m})$ were observed to enter the aerosol inlet. While the preliminary wind-tunnel tests provided initial validation of CFD results, aircraft deployment of the inlet was critical for its full evaluation. Aircraft testing of the BASE was conducted with the inlet deployed on the NSF (National Science Foundation)/NCAR (National Center for Atmospheric Research) C-130 aircraft in two field campaigns: Profiling of Winter Storms (PLOWS) and Ice in Cloud Experiment - Tropics (ICE-T). The aircraft testing procedure, inlet performance results, and inlet design iterations are described below.

\section{Flight tests}

\subsection{First iteration: BASE-I}

The first design iteration of the BASE, referred to here as BASE-I, was flown on NSF/NCAR C-130 aircraft during the PLOWS (Profiling of Winter Storms; November 2009March 2010) campaign. The primary objective for the deployment of BASE-I in PLOWS was to test the inlet performance under actual flight conditions and compare the obtained data with the wind-tunnel and CFD results of Moharreri et al. (2013). The major dimensions and assembly components of the aircraft version of BASE-I are shown in Fig. 2. All parts of the inlet were machined from Al-6063 and anodized for corrosion protection. Four $100 \mathrm{~W}$ cartridge heaters (Watlow) and a $1000 \Omega$ miniature embedment RTD (resistance temperature detector) (Minco) were embedded in the blunt body housing and connected to a controller circuit to de-ice the sampler when required. The aerosol sample was transported to the cabin through a $\sim 2 \mathrm{~m}$ long $1 / 4 \mathrm{in}$. flexible conductive tubing (TSI Inc.). To help keep the boundary 
layer attached, a suction port was located just upstream of the inlet. Suction flow from this port was connected to a passive venturi pump mounted on the side of the aircraft using a $3 / 4$ in. flexible fireproof hose (Parker Inc.).

Three aerosol samplers were flown during the PLOWS campaign, with the purpose of intercomparing their performance in clouds. The three tested inlets were: BASE-I, NCAR HIAPER Modular Inlet (HIMIL), and NCAR's submicron aerosol inlet (SMAI). The HIMIL is a sharp-edge, forward-facing diffuser modular inlet design that can be assembled to provide gas or aerosol sampling (Stith et al., 2009; UCAR, 2011). NCAR's SMAI was initially developed for gas sampling, but was recently shown to have promise as an interstitial aerosol sampler (Craig et al., 2013a, b). The SMAI design has a flow-through cone with a cross-flow sample tube located inside it. The presence of the cone results in a decelerated flow upstream of the inlet and reduced flow velocity (relative to aircraft velocity) within the inlet. These design features result in cloud particles impacting on the inlet body at reduced speeds relative to forward-facing probes. Craig et al. (2013a) show that the SMAI aerosol samples were largely free of shatter when the mean cloud droplet sizes were smaller than $\sim 16 \mu \mathrm{m}$. In clouds with large droplet sizes and drizzle drops, the $\mathrm{CN}$ concentrations measured by the SMAI were enhanced because of the presence of shatter particles, but the magnitude of enhancement was significantly lower than that observed with forward-facing probes. The details of the SMAI design and its sampling characteristics are discussed in Craig et al. (2013a, b).

The three aerosol inlets were installed on the belly of the aircraft hull, towards the aft, and in close proximity to one another. The BASE was mounted $\sim 14 \mathrm{~m}$ behind the aircraft nose and $\sim 1.5 \mathrm{~m}$ off the centerline of the aircraft fuselage to the right side. The SMAI was installed $\sim 15 \mathrm{~m}$ behind the aircraft nose on the centerline of the fuselage and the HIMIL was mounted $\sim 14 \mathrm{~m}$ behind the aircraft nose and $\sim 1.5 \mathrm{~m}$ off the centerline to the left side. A picture of the inlets mounted on the C-130 belly was shown in Moharreri et al. (2013).

A variety of microphysical and state parameters were measured on the aircraft, and the resulting data were used for performance analysis of BASE-I. Particle concentrations from BASE-I, the SMAI, and the HIMIL inlets were measured using three condensation particle counters (CPCs): TSI 3010, TSI 3760a, and a modified, low-pressure TSI 3786, respectively. Size distribution and concentrations of cloud particles in the size range of $2-50 \mu \mathrm{m}$ were measured by NCAR/RAF using a cloud droplet probe (CDP; Droplet Measurement Technologies) and a forward-scattering spectrometer probe (FSSP-100; Particle Measurement System; Dye and Baumgardner, 1984). The larger cloud particles (drizzle, if in warm clouds; 50-1600 $\mu \mathrm{m}$ size range) were measured using an imaging technique with a two-dimensional cloud probe (2D-C; Particle Measuring Systems). Cloud liquid water content was measured using a "PMS King" probe (Particle Measuring Systems). To characterize the nature of flow around the blunt body and compare flow simulation results with actual flight conditions, pressure measurements were made at six different locations on the blunt body housing using an Esterline pressure scanner (model 9116).

\subsubsection{CN measurements in liquid clouds}

In designing BASE-I, the presence of only liquid droplets was considered, and, correspondingly, an appropriate comparison of model predictions with measurements must only consider inlet data obtained in warm clouds. PLOWS campaign flights were mostly out of Peoria, IL, USA, in the geographic range of $32-48^{\circ} \mathrm{N}$ and $81-104^{\circ} \mathrm{W}$. The altitude range covered was $900-8500 \mathrm{~m}$ and the aircraft speed range was $\sim 125-150 \mathrm{~m} \mathrm{~s}^{-1}$. During the PLOWS campaign most cloud penetrations were through ice clouds, though warm liquid clouds were encountered during one flight (PLOWS ferry flight PLOWSff03 - 3 November 2009). The BASE-I performance analysis presented here is based on data obtained during this warm-cloud passage.

For a selected cloud penetration case, time series plots of cloud and drizzle concentrations and the corresponding particle concentrations measured from the three aerosol inlets flown during PLOWS are shown in Fig. 3. For this case, the average temperature during the analysis time period was $-0.4{ }^{\circ} \mathrm{C}$, and, therefore, the cloud particles/droplets are likely to be in liquid phase (Korolev et al., 2003). During this measurement period the concentration of drizzle was negligible. For this drizzle-free, liquid-cloud penetration case, $\mathrm{CN}$ measurements from a traditional aerosol inlet (HIMIL) were significantly enhanced in the presence of cloud droplets, suggesting contamination of the sample with shatter particles. The CN concentrations obtained from BASE-I and the SMAI were, however, seen to be depleted relative to the out-ofcloud samples. This observation is consistent with the expectation that a fraction of the background aerosol will be activated to form clouds and, thus, the interstitial fraction should be lower than the background aerosol concentration. The depletion of CN concentrations in BASE-I and SMAI samples were, however, seen to be different for the two inlets. The difference in the measurements of the SMAI and BASE-I could be because of the differing cut sizes of the two inlets or because of the locational differences of the inlets and/or possibly indicative of differing shatter artifacts in the two inlets. To understand the possible contribution of shatter to the measurements of the two inlets, a $\mathrm{CN}$ cloud droplet closure analysis was conducted by comparing the out-of-cloud $\mathrm{CN}$ concentrations with the sum of the in-cloud $\mathrm{CN}$ and cloud concentrations (FSSP-100) for the two inlets (Fig. 3). With BASE-I CN concentrations, a reasonable closure is achieved at most times, while with the SMAI CN concentrations, the in-cloud values $(\mathrm{CN}+\mathrm{FSSP}-100)$ are seen to be lower that the out-of-cloud $\mathrm{CN}$ concentration values.

The accuracy of this analysis to determine relative performance of the two inlets is, however, compromised by the 


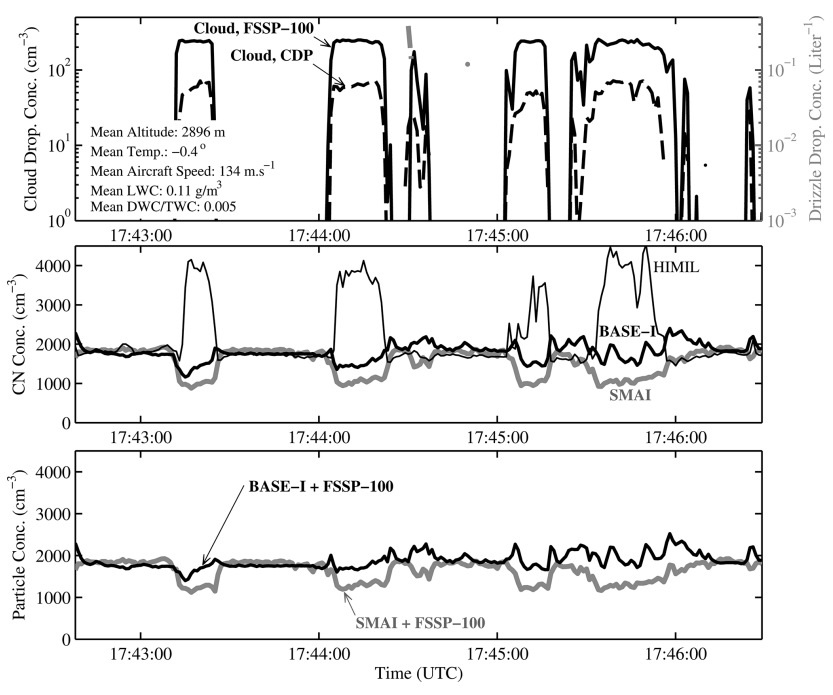

Figure 3. Performance of three aerosol inlets on the C-130 aircraft during a drizzle-free cloud penetration during PLOWSff03 (3 November 2009) flight. LWC: liquid-water content from the King probe; DWC: drizzle-water content from 2D-C probe; TWC (total water content $)=\mathrm{DWC}+\mathrm{LWC}$.

lack of information about aerosol concentrations in the precloud (or below-cloud) air mass. Another source of uncertainty in this analysis is the accuracy of cloud concentration values. Cloud concentrations measured by the two cloud probes flown during the campaign (CDP and FSSP-100) often differed significantly. This is not completely unexpected. The CDP has a low detection efficiency for small ice particles (Allen Schanot, NCAR, personal communication, 2014) while shatter artifacts are known to affect FSSP-100 measurements (McFarquhar et al., 2007). These problems result in a significant uncertainty in $\mathrm{CN}$ cloud droplet closure analysis.

In the presence of drizzle (Fig. 4), $\mathrm{CN}$ measurements made by BASE-I and HIMIL were seen to be significantly elevated. The shatter contamination seen in BASE-I data was likely because, for large incoming particles/droplets, a significant fraction of secondary particles generated from impaction may be larger than $2 \mu \mathrm{m}$ and the CFD simulations of Moharreri et al. (2013) suggested that shatter particles in that size range will enter the aerosol sample. Thus, it could be concluded that shatter-free sampling of interstitial aerosol measurements is possible with the BASE-I design but only in the absence of drizzle/precipitation droplets.

\subsubsection{Pressure distribution around the blunt body}

To validate CFD flow calculations, pressure measurements were made at six locations on the bunt body housing on BASE-I: the front stagnation region, the maximum-diameter region of the housing, and four locations in the aft region of the blunt body. The four aft pressure ports were at the
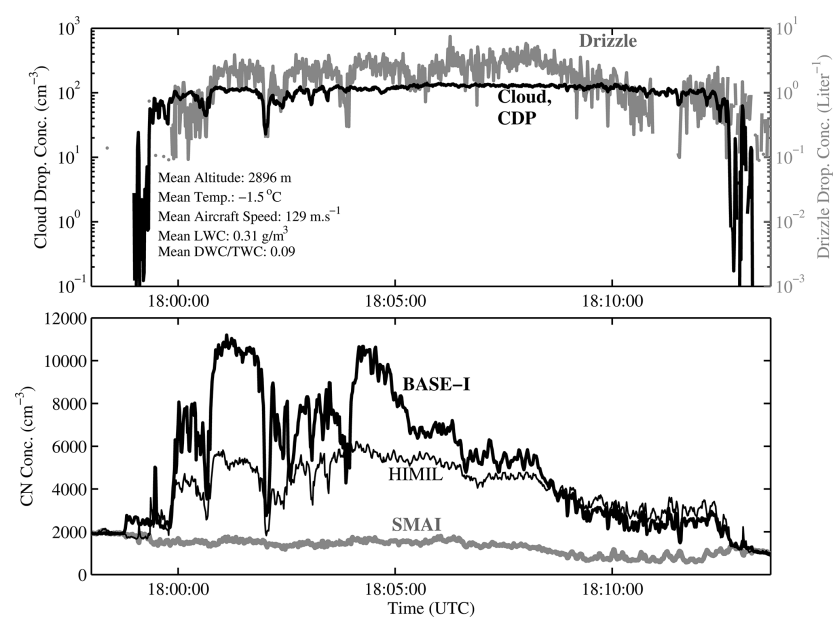

Figure 4. Performance of three aerosol inlets on the C-130 aircraft during a cloud penetration in the presence of drizzle. Data from PLOWSff03 (3 November 2009) flight.

same streamwise distance along the chord length of the housing, spaced $45^{\circ}$ apart azimuthally. These ports were placed to determine if the flow was axisymmetric around the blunt body housing. Pressure distribution measurements from typical flight conditions (Ma 0.4 and $600 \mathrm{mbar}$ to $M a 0.45$ and 400 mbar range) during testing of BASE-I are compared against CFD predictions in Fig. 5. The CFD simulation results were obtained following the procedure of Moharreri et al. (2013), using the $k-\omega$ SST (shear stress transport) turbulence model for boundary conditions consistent with flight data. Good agreement between the CFD predictions and measurement data was observed when the altitudes were below $\sim 21000 \mathrm{ft}$ (Fig. 5a). For altitudes above $\sim 21000 \mathrm{ft}$ (static pressure lower than $\sim 450 \mathrm{mbar}$ ), however, the pressure coefficients obtained from measurements differed considerably from the CFD predictions. At the maximum-diameter region of the blunt body housing, the measured pressures were higher than the numerically predicted values, and these pressures were also seen to have significant fluctuation (as indicated by the large error bars for this data in Fig. 5b). Also, pressures at the aft ports in the free-stream side of the blunt body housing (i.e., away from the aircraft skin) were slightly lower than expected. The lower pressures in the aft region of the blunt body suggest that boundary layer separation occurred at high altitudes.

The deviation between measured and CFD-predicted pressure distributions can be partly attributed to the mismatch between the flight conditions considered initially during the design stage ( $800 \mathrm{mbar}, 100 \mathrm{~ms}^{-1}$ ) and those encountered during PLOWS (significant periods with pressures $<450 \mathrm{mbar}$ and airspeeds $>140 \mathrm{~ms}^{-1}$ ). At low-altitude conditions of $800 \mathrm{mbar}$ and $100 \mathrm{~ms}^{-1}$ (the conditions used for BASE-I design), the Reynolds number around the blunt body was $\sim 8 \times 10^{5}$. For the higher-altitude conditions seen in PLOWS, 


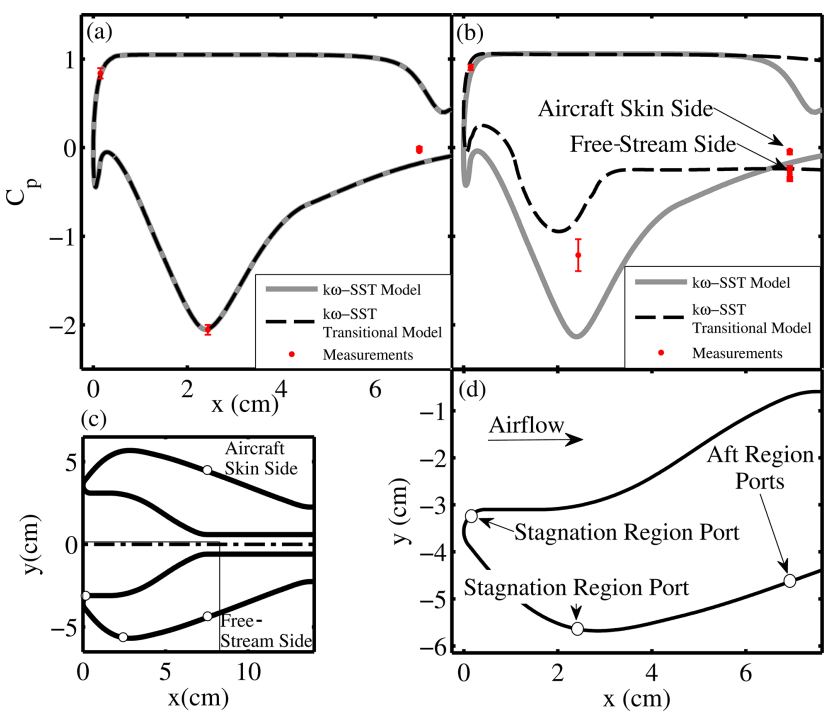

Figure 5. Comparison of pressure measurements around the blunt body housing with simulation results. The experimental data are from the PLOWS research flight PLOWSrf01, 13 November 2009 flight. (a): low-altitude case; experimental data from the period of 17:00 to 18:00 UTC; simulation boundary conditions: $600 \mathrm{mbar}$, Ma 0.4; (b): high-altitude case; experimental data from the period of 18:32 to 19:05 UTC; simulation boundary conditions: $400 \mathrm{mbar}$, Ma 0.45 ; values reported are pressure coefficient $\left(C_{p}=\frac{p-p_{\infty}}{1 / 2 \rho V^{2}}\right)$; (c): cut-out view of BASE-I with the different pressure ports on its surface; (d): zoomed-in view of the box shown in (c) showing locations of the pressure measurement ports.

the Reynolds numbers were lower $\left(\sim 6 \times 10^{5}\right)$, and for these conditions, accurate predictions require the use of models that can resolve changes in boundary layer flow in the transitional regime, such as the $k-\omega$ SST transitional model in FLUENT 6.2.3 (FLUENT user manual, 2006).

New CFD simulations of flow around the blunt body were conducted with an axisymmetric, $k-\omega$ SST transitional model, and results are shown in Fig. 5. The model results were seen to have a reasonable agreement with the measured pressures at both high and low altitudes. In addition, at high altitudes, the $k-\omega$ SST transitional model accurately predicted flow separation in the aft region of the blunt body housing, as observed by the model results of the relatively constant value of the pressure coefficient $\left(C_{p}\right)$ in this region. The differences in the pressures measured in the aft-region of the blunt body on the two opposite sides of the sampler (Fig. 5b) - aircraft-side and free-stream side - suggest that axisymmetric assumption of flow field around the sampler is not entirely accurate. The presence of the aircraft skin and the strut connecting blunt body housing to the aircraft skin result in a non-axisymmetric or three-dimensional flow field around the sampler, and accurate description of this flow field requires three-dimensional (3-D) simulations considering the full details of the sampler geometry.

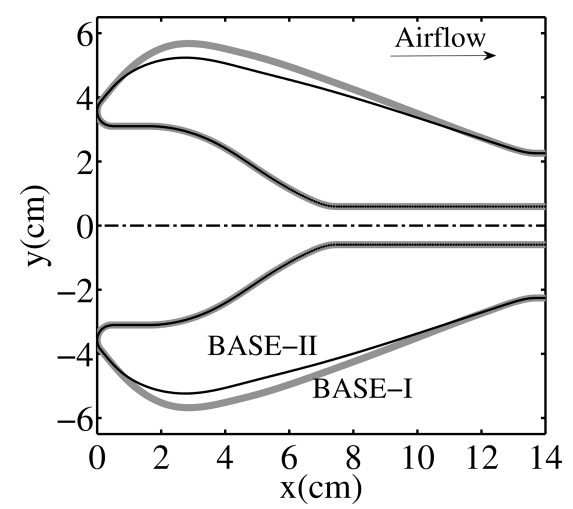

Figure 6. Profiles of the blunt body housing for BASE-I and BASEII designs.

\subsection{BASE-II}

From the data obtained during the PLOWS campaign, it was determined that the BASE-I design needed to be modified to address the problems of boundary layer separation at high altitudes and shatter-artifact contamination in the sample flow in the presence of drizzle drops. Using the new CFD simulation results obtained with the $k-\omega$ SST transitional turbulence model, the BASE-I blunt body shape was streamlined such that separation-free flow fields were possible for all flight conditions encountered during PLOWS. The profile alteration is shown in Fig. 6, and the sampler with the modified profile is referred to here as BASE-II. BASE-II was fabricated and flown during the second half of the PLOWS campaign (January-March 2010) and during ICE-T (2011) campaign. For better characterization of the pressure distribution around the sampler, several additional pressure taps (a total of 11) were added to the blunt body of BASE-II.

To address the shatter-contamination issue, it was first necessary to determine the shatter particle sizes that will be present in the sample flow. Following the approach of Moharreri et al. (2013), particles of different sizes were injected onto the surface of the blunt body housing with a range of normal velocities, and their resulting trajectories were tracked. From the analysis of these trajectories, the shatter particle sampling efficiencies of the interstitial inlet were determined, as shown in Fig. 7 for flight conditions of 400 mbar and $M a 0.45$. Each line in Fig. 7 represents results for sampling efficiency of shatter particles as a function of particle size and for a constant injection normal velocity. The modeling results suggest that, almost independent of particle injection velocity, only shatter particles larger than $\sim 2 \mu \mathrm{m}$ aerodynamic diameter are sampled into the inlet. This is consistent with the original design criteria and predictions of BASE-I performance, as established in Moharreri et al. (2013). The sampling efficiency is expected to be maximal for shatter particles of a diameter of $\sim 3 \mu \mathrm{m}$. The largest particle sizes that may be present in the sampling volume of 


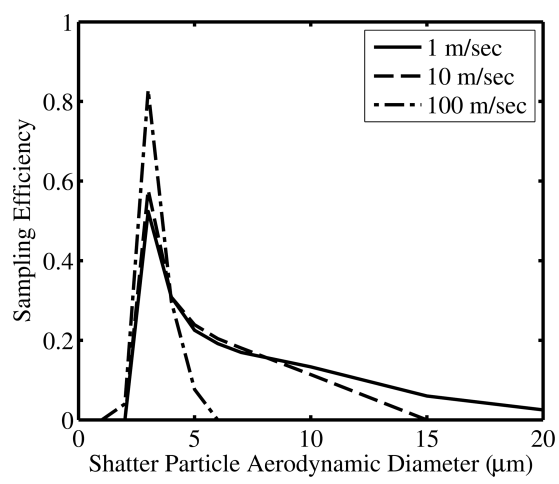

Figure 7. Sampling efficiency (number sampled/number injected at the surface) of shatter particles of different sizes injected onto the surface of the blunt body housing for three values of normal velocity: 1,10 , and $100 \mathrm{~ms}^{-1}$. Flight conditions are $400 \mathrm{mbar}$ and Ma 0.45 .

the interstitial inlet are, however, strongly dependent on the normal ejection velocities of the particles.

In designing BASE-I, the scenario of large droplets and drizzle in a sampled cloud system was not considered and, hence, the possibility of a significant number of shatter particles larger than $2 \mu \mathrm{m}$ entering the inlet was ignored. From the shatter sampling efficiency results of Fig. 7, it can be concluded that an interstitial inlet that only samples particles smaller than $\sim 2 \mu \mathrm{m}$ will be largely free of shatter artifact particles. To accomplish this goal, the interstitial inlet design was modified as a cross-flow sampling inlet, as shown in Fig. 8. In this new design, the inlet tube was modified to be a flow-through tube with a flow-restriction nozzle at its exit. The sample flow was extracted from the flow-through tube at an angle of $\sim 80^{\circ}$, ensuring that only particles smaller than a cut size will be sampled. The sampling efficiency of such a cross-flow sampling inlet is largely determined by the size of the flow-constricting nozzle (Craig et al., 2013b). Using 3-D CFD simulations, the appropriate size of the flowconstricting nozzle required for a $2 \mu \mathrm{m}$ sampling cut size was determined. For simplicity, these simulations were conducted by ignoring the blunt body, but considering the flow conditions at the inlet location determined from earlier blunt body simulations. The calculated sampling efficiency of the final cross-flow sampling inlet is shown in Fig. 9.

The updated BASE-II design with the new cross-flow tube inlet was flown on the NSF/NCAR C-130 during the ICE$\mathrm{T}$ (2011) campaign. In addition to the $\mathrm{CN}$ measurements and pressure distributions around the blunt body, the size distributions of the sampled particles were obtained using a UltraHigh Sensitivity Aerosol Spectrometer (UHSAS; DMT Inc.) and a High-flow Dual channel Differential Mobility Analyzer (HDDMA; Dubey, 2010). Bypass flows were used to increase the sampling flow rate and minimize the transit time of the particles from the inlet to the instrumentation inside the cabin.

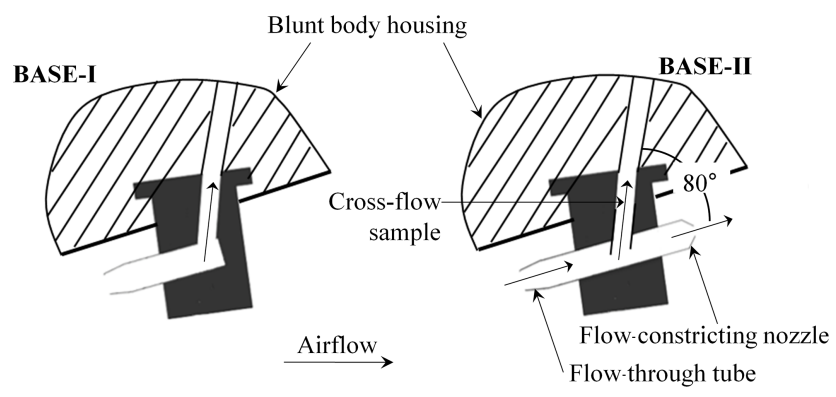

Figure 8. Schematic diagram of the interstitial inlet designs in BASE-I (left) and BASE-II (right).

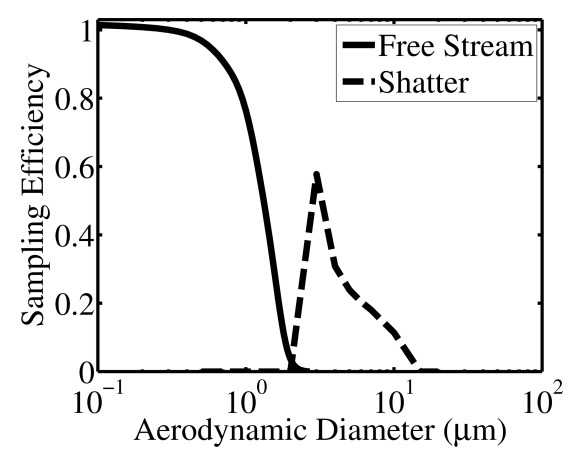

Figure 9. The cut size of the cross-flow sampling tube of BASEII. Also shown is the size-dependent fraction of shatter particles that will be present in the sampling flow region of the cross-flow sampling inlet. Flight conditions are 400 mbar and $M a 0.45$; shatter particles were injected at a normal velocity of $10 \mathrm{~m} \mathrm{~s}^{-1}$.

\subsubsection{Pressure measurements around the blunt body housing}

Pressure measurements made during flight testing of BASEII suggest excellent agreement with CFD predictions for all pressure ports, and the flow was seen to be attached around the blunt body housing for all aircraft speeds and altitudes encountered. As an example, a comparison of the measurement data with predictions of CFD simulations using the $k-\omega$ SST transitional turbulent model is shown in Fig. 10 for 400 mbar and $M a 0.47$ conditions. These pressure measurements suggest that the modified profile eliminates the problem of flow separation at higher altitudes observed with BASE-I, making BASE-II deployable for the entire range of C-130 flight conditions.

\subsubsection{Sampling efficiency}

The overall sampling efficiency of the BASE-II cross-flow inlet was calculated as a product of two effects: (i) the influence of the blunt body housing on the particle concentration at the inlet location and (ii) the sampling efficiency for a cross-flow inlet. Flow around the curvature of the blunt body results in inertial focusing of particles of a certain size 


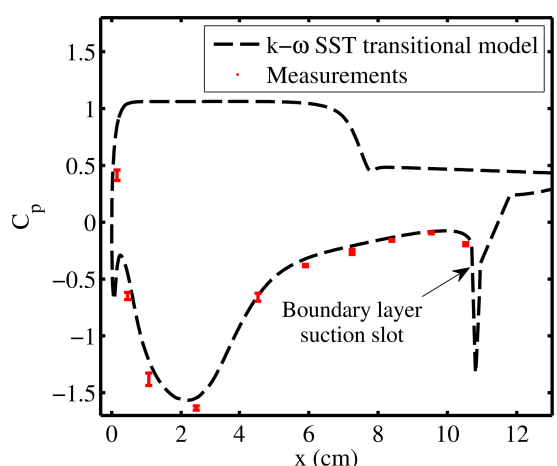

Figure 10. Pressure distribution around the blunt body housing of BASE-II. Data from ICE-Trf04 (11 July 2011, 16:15-16:20 UTC); Simulation boundary conditions: $P=400 \mathrm{mbar}, \mathrm{Ma} 0.47$.

range as they are transported to the aft region. The details of the particle-focusing effect and its effect on the particle concentration at the inlet location are discussed in Moharreri et al. (2013). The relative concentration of particles of different diameters at the inlet entrance to that in the free stream is shown in Fig. 11a (indicated as blunt body effect). To determine the sampling efficiency of the cross-flow inlet, CFD simulations were conducted by modeling just the internal flow in the inlet on the blunt body. The boundary conditions of flow velocities at the inlet entrance were obtained from the CFD calculations of external flow around the blunt body housing. After calculation of the internal flow fields, trajectories of particles of different diameters were tracked through the inlet geometry and the sampling efficiency of the cross-flow inlet tube was determined and are shown in Fig. 11a (indicated as cross-flow inlet effect). The net sampling efficiency of BASE-II, obtained as a convolution of the cross-flow sampling and blunt body effects, is also shown in Fig. 11a. The net sampling efficiency is seen to be $\sim 1$ for all particles smaller than $1 \mu \mathrm{m}$, and particles larger than $\sim 2 \mu \mathrm{m}$ are not sampled by the new cross-flow inlet.

To validate the overall sampling performance of the BASE inlet, out-of-cloud aerosol size distributions measured by the BASE using a UHSAS $(0.055$ to $1 \mu \mathrm{m})$ and the HDDMA (10 to $300 \mathrm{~nm}$ ) instruments were compared with those obtained from two wing-mounted instruments: the passive cavity aerosol spectrometer probe (PCASP; PMS Inc; $0.1-3.0 \mu \mathrm{m}$ ) and the forward-scattering spectrometer probe (FSSP-300; PMS Inc., 0.3-20 $\mu \mathrm{m})$. For accurate comparison, care was taken to identify time periods when cloud particles were absent, flight parameters were constant, and data from all relevant particle size measurement instruments were available. The comparison of the size distributions from the two sets of measurements (Fig. 11b) suggests a reasonable match in the overlapping measurement size range of 0.1 to $1 \mu \mathrm{m}$. This provides initial validation of the model predictions of inlet sampling efficiency of $\sim 1$ for submicron particles.
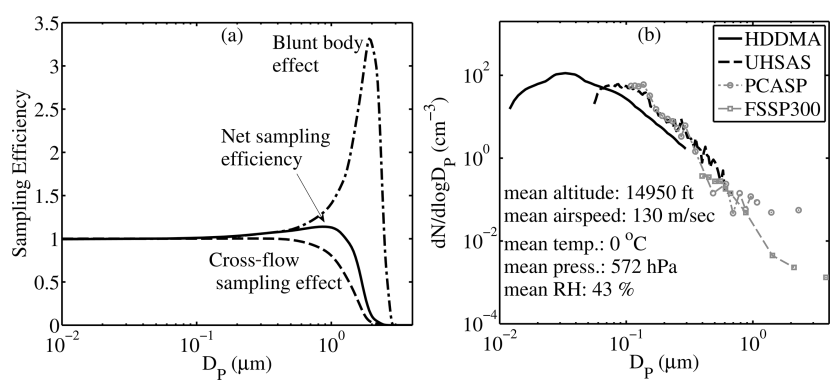

Figure 11. (a) Model-predicted sampling efficiency for BASE-II; (b) measured aerosol size distribution from BASE-II compared with the free-stream measurements in clear air. Measurement data from ICE-Trf04 (11 July 2011, 17:39:00-17:49:30 UTC). HDDMA and UHSAS were connected to BASE-II aerosol samples while PCASP and FSSP-300 were wing-mounted, measuring particle concentrations from the free-stream air.

\subsubsection{CN measurements in warm clouds}

During ICE-T, there were several warm-cloud passages, providing significant data for analysis of BASE-II performance in the presence of liquid droplets. For the current analysis, a cloud event was identified as being when the average cloud droplet concentration measured by the FSSP-100 was $>5 \mathrm{~cm}^{-3}$ for at least $10 \mathrm{~s}$. Average "ambient-air" aerosol concentrations associated with a cloud event were obtained from a $10 \mathrm{~s}$ time interval prior to the start of that cloud event, where the average cloud droplet concentrations were $<5 \mathrm{~cm}^{-3}$.

The ratio of aerosol concentration in a selected cloud system to that in the ambient air in its vicinity is referred to as "CN Enhancement". Enhancement values greater than 1 are usually indicative of shatter artifacts in $\mathrm{CN}$ measurements (Craig et al., 2013b). To facilitate a direct comparison of the performance of the two BASE designs, the BASE CN enhancement values were normalized using $\mathrm{CN}$ enhancements from the SMAI as a reference sampler. The normalized enhancements allowed the comparison of the performances of BASE-I and BASE-II regardless of differences in the droplet size distribution and flight conditions (aircraft speed, angle of attack, roll, etc.) experienced by the two inlets. The SMAI (Craig et al., 2013a) was chosen as a reference sampler because it was previously shown to be minimally affected by shatter artifacts during in-cloud sampling (Craig et al., 2013b). Also, for both PLOWS and ICE-T campaigns, the operation and location of the SMAI was identical relative to the BASE, making it an optimal reference sampler.

The BASE CN enhancements normalized with the corresponding SMAI measurements are shown in Fig. 12. Note that the BASE-I data considered here corresponded to loweraltitude flights, where the flow around the blunt body was largely attached. The BASE-I CN enhancements are significantly higher than the SMAI values when the mean cloud droplet sizes are larger than $12 \mu \mathrm{m}$, while the $\mathrm{CN}$ enhancements of BASE-II are lower than those of the SMAI at all 


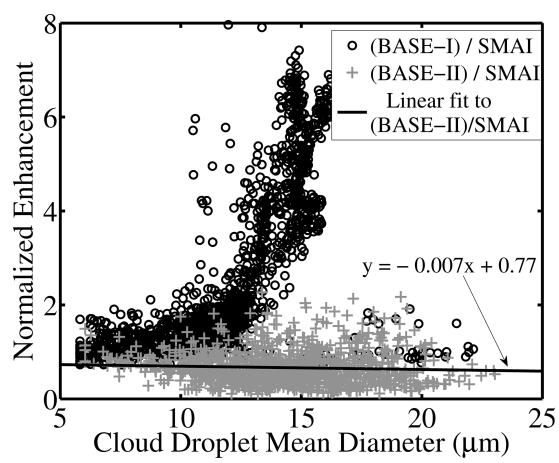

Figure 12. In-cloud CN enhancements of BASE-I and BASE-II, normalized by the enhancement values of the SMAI at each data point. Data from all PLOWS and ICE-T campaign flights; atmospheric conditions: temperatures $--5-1{ }^{\circ} \mathrm{C}$; cloud droplet mean diameter $-5-25 \mu \mathrm{m}$; drizzle concentration $-<300 \mathrm{~L}^{-1}$; drizzle mean droplet diameter $-<600 \mu \mathrm{m}$; aircraft true airspeed $-125-150 \mathrm{~ms}^{-1}$; LWC - 0-0.4 $\mathrm{g} \mathrm{m}^{-3}$; DWC/TWC - 0-1.

cloud droplet diameters. The BASE-II CN enhancements are seen to slightly decrease with increasing mean cloud droplet size. This comparison suggests that the shatter artifacts with the BASE-II design are significantly lower than with BASE-I design and also lower than that seen in the SMAI.

The flight test results suggest that the BASE design provides effective interstitial aerosol sampling under a range of ambient conditions. The BASE principle can be extended to design interstitial inlets for other platforms operating under different conditions. While the BASE design represents a significant advance in interstitial aerosol sampling, there is a need for continued development and improvement in the sampler design, as the data suggest that some shatter artifacts may still be present in the BASE sample. It is possible that the observed enhancements during in-cloud measurements made by the BASE are not because of shatter artifacts in the inlet but because of the choice of the background ambient aerosol, because of droplet shatter resulting from their impaction on the aircraft fuselage, or because of shatter artifacts from inlets/objects upstream of the BASE. Turbulent dispersion of shatter particles as they flow around the blunt body housing could also result in shatter contamination of BASE samples. Turbulence can act to disperse shatter particles from near the blunt body surface and bring them into the flow that is sampled by the interstitial inlet. Further studies that consider the role of the aircraft hull and turbulent particle transport are required to improve characterization of the BASE sampler and to propose any further design modifications necessary to improve its performance.

\subsubsection{Performance in cold clouds}

The initial goal of BASE deployment was sampling inside young cumulus clouds, with the expectation that the cloud droplets encountered would be primarily in liquid phase.

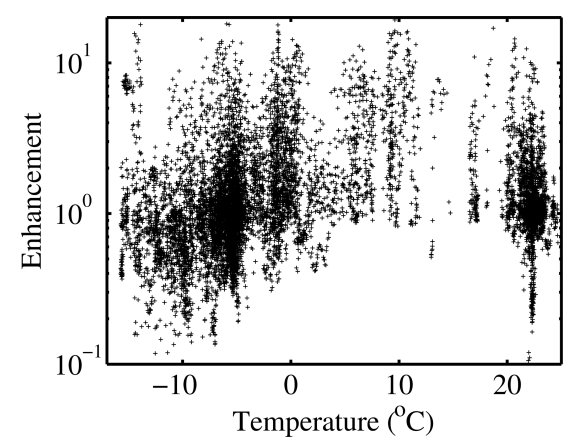

Figure 13. Variation of $\mathrm{CN}$ enhancements of BASE-II with temperature. At temperatures below $-5^{\circ} \mathrm{C}$, lower enhancements are seen, indicating a reduced shatter-artifact problem with ice particles relative to liquid droplets.

During the initial field deployment, however, ice and snow were encountered during several flights. The wide variety of ice and snow particle types that may be present in the atmosphere prevent any simple parametric analysis of sampler performance. In general, breakup mechanisms and characteristics of shatter particles depend on a number of factors including the shape of crystals, the crystal structure, and the angle of each individual impaction event. From past observations (Craig et al., 2013b; Weber et al., 1998), the general expectations are that the impaction of ice and snow particles on the sampler will result in the generation of fewer shatter particles that are, on average, larger in size than shatter particles generated from the breakup of liquid droplets. This expectation was confirmed with observations made with BASEII, where smaller enhancement values are observed at lower temperatures in general (Fig. 13). Further studies considering detailed modeling of solid-particle impaction on the inlet are, however, required for a full understanding of the inlet performance in cold clouds.

\section{Conclusions}

The sampling performance of a new Blunt-body Aerosol Sampler (BASE) was established from measurements made on the NSF/NCAR C-130 aircraft. The initial version of the inlet (BASE-I), designed entirely from CFD simulations, was seen to sample shatter-free aerosol in low-altitude, warm clouds in the absence of drizzle. In the presence of drizzle drops or when operated at high altitudes, BASE performance was, however, observed to be similar to standard aerosol inlets, with significant shatter contamination of $\mathrm{CN}$ measurements. The initial aircraft test results were utilized to improve the design of the blunt body and the aerosol inlet on the body. Pressure measurements around the redesigned sampler (BASE-II) revealed that the flow field around the sampler was as predicted by CFD simulations. Comparison of BASE-II performance with that of another interstitial inlet 
(the SMAI) showed that BASE-II samples were minimally contaminated with shatter artifacts over a wide range of atmospheric conditions. The BASE sampler thus represents a significant progress in our efforts to probe the characteristics of interstitial aerosol, and the design of this inlet can be extended to other aircraft operating conditions, enabling the study of a large range of cloud systems.

In general, the best-designed interstitial inlets will still experience variable and unknown shatter artifacts. Our analysis presented in this submission and past published papers (Craig et al., 2013a, b) suggests that, with well-designed interstitial inlets, shatter artifacts should be minimal under most conditions and shatter-free sampling may even be possible under some conditions. Going forward, a recommended sampling strategy for interstitial aerosol would be to fly (at least) two interstitial inlets of different designs (e.g., BASE-II and the SMAI). As the shatter-artifact contribution to an inlet's sample is strongly dependent on its geometry, shatter-free sampling will be assured when matched-number concentration measurements are obtained from these two very different samplers. Physical and chemical measurements of such samples, coupled with analyses such as those presented in Kleinman et al. (2012), will enable us to arrive at stronger conclusions about particle activation and help improve aerosolcloud parameterizations.

Acknowledgements. The authors would like to kindly acknowledge financial support from NSF (AGS-0548036; 1121915) and aircraft testing assistance provided by NCAR RAF staff. We thank Jeff Snider for his detailed review of our manuscript. We also thank Al Schanot of NCAR for useful discussions about cloud probes flown on the $\mathrm{C}-130$ and their measurement artifacts.

Edited by: J. Schneider

\section{References}

Craig, L., Moharreri, A., Schanot, A., Rogers, D. C., Anderson, B., and Dhaniyala, S.: Characterizations of Cloud Droplet Shatter Artifacts in Two Airborne Aerosol Inlets, Aerosol Sci. Technol., 47, 662-671, 2013a.

Craig, L., Schanot, A., Moharreri, A., Rogers, D. C., and Dhaniyala, S.: Design and Sampling Characteristics of a New Airborne Aerosol Inlet for Aerosol Measurements in Clouds, J. Atmos. Ocean. Tech., 30, 1123-1135, 2013 b.

Dubey, P.: Fast scanning electrical mobility spectrometry: Theory, experiments, and inversion methodologies, PhD Thesis, 2010.

Dye, J. E. and Baumgardner, D.: Evaluation of the Forward Scattering Spectrometer Probe. Part I: Electronic and optical studies, J. Atmos. Ocean. Tech., 1, 329-344, 1984.

FLUENT 6.3 User's Guide: Fluent, Inc., Lebanon, NH, USA, 2006.

Forster, P., Ramaswamy, V., Artaxo, P., Berntsen, T., Betts, R., Fahey, D.W., Haywood, J., Lean, J., Lowe, D.C., Myhre, G., Nganga, J., Prinn, R., Raga, G., Schulz, M., and Van Dorland, R.: Changes in Atmospheric Constituents and in Radiative Forcing, in: Climate Change 2007: The Physical Science Basis. Con- tribution of Working Group I to the Fourth Assessment Report of the Intergovernmental Panel on Climate Change, edited by: Solomon, S., Qin, D., Manning, M., Chen, Z., Marquis, M., Averyt, K. B., Tignor, M., and Miller, H. L., Cambridge University Press, Cambridge, United Kingdom and New York, NY, USA, 2007.

Kleinman, L. I., Daum, P. H., Lee, Y.-N., Lewis, E. R., Sedlacek III, A. J., Senum, G. I., Springston, S. R., Wang, J., Hubbe, J., Jayne, J., Min, Q., Yum, S. S., and Allen, G.: Aerosol concentration and size distribution measured below, in, and above cloud from the DOE G-1 during VOCALS-REx, Atmos. Chem. Phys., 12, $207-$ 223, doi:10.5194/acp-12-207-2012, 2012.

Korolev, A.: Shattering during Sampling by OAPs and HVPS. Part I: Snow Particles, J. Atmos. Ocean. Tech., 22, 528-542, 2005.

Korolev, A. V., Isaac, G. A., Cober, S. G., Strapp, J. W., and Hallett, J.: Micrphysical Characterization of Mixed-Phase Clouds, Q. J. Roy. Meteorol. Soc., 129, 39-65, 2003.

Korolev, A. V., Emery, E. E., Strapp, J. W., Cober S. G., Isaac, G. A., Wasey, M., and Marcotte, D.: Small Ice Particles in Tropospheric Clouds: Fact or Artifact?, B. Am. Meteorol. Soc., 91, 967-973, doi:10.1175/2010BAMS3141.1, 2011.

Korolev, A. V., Emery, E. F., Strapp, J. W., Cober, S. G., and Isaac, A.: Quantification of the Effects of Shattering on Airborne Ice Particle Measurements, J. Atmos. Ocean. Tech., 30, 2527-2553, doi:10.1175/JTECH-D-13-00115.1, 2013.

Lohmann, U. and Feichter, J.: Global indirect aerosol effects: a review, Atmos. Chem. Phys., 5, 715-737, doi:10.5194/acp-5-7152005, 2005.

McFarquhar, G. M., Um, J., Freer, M., Baumgardner, D., Kok, G. L., and Mace, G.: Importance of small ice crystals to cirrus properties: Observations from the Tropical Warm Pool International Cloud Experiment (TWP-ICE), Geophys. Res. Lett., 34, L13803, doi:10.1029/2007GL029865, 2007.

Moharreri, A., Craig, L., Rogers, D. C., and Dhaniyala, S.: A New Aircraft Inlet for Sampling Interstitial Aerosol: Design Methodology, Modeling, and Wind Tunnel Tests, Aerosol Sci. Technol., 47, 885-894, 2013.

Penner, J. E., Quaas, J., Storelvmo, T., Takemura, T., Boucher, O., Guo, H., Kirkevåg, A., Kristjánsson, J. E., and Seland, Ø.: Model intercomparison of indirect aerosol effects, Atmos. Chem. Phys., 6, 3391-3405, doi:10.5194/acp-6-3391-2006, 2006.

Rogers, D. C.: An observational study of cloud particles splash/breakup artifacts on air sampling from inlets, 15th Intl. Conf. Clouds \& Precipitation, Cancun, Mexico, 2008.

Schlichting, H., Gersten, K., Krause, E., Oertel Jr., H., and Mayes, C.: Boundary-Layer Theory, 8th Edn., Springer, 2004.

Stith, J. L., Ramanathan, V., Cooper, W. A., Roberts, G. C., DeMott, P. J., Carmichael, G., Hatch, C. D., Adhikary, B., Twohy, C. H., Rogers, D. C., Baumgardner, D., Prenni, A. J., Campos, T., Gao, R., Anderson, J., and, Feng, Y.: An overview of aircraft observations from the Pacific Dust Experiment campaign, J. Geophys. Res., 114, D05207, doi:10.1029/2008JD010924, 2009.

UCAR: NCAR, RAF Air Sample Inlets for RAF Aircraft, update January 2011, available at: http://www.eol.ucar.edu/homes/ dcrogers/Instruments/Inlets/ (last access: 10 August 2014), 2011.

Weber, R. J., Clarke, A. D., Litchy, M., Li, J., Kok, G., Schillawski, R. D., and McMurry, P. H.: Spurious aerosol measurements when sampling from aircraft in the vicinity of clouds, J. Geophys. Res.Atmos., 103, 28337-28346, 1998. 